Check for updates

Cite this: Phys. Chem. Chem. Phys., 2020, 22, 11327

Received 12th March 2020, Accepted 6th May 2020

DOI: $10.1039 / \mathrm{d} 0 \mathrm{cp} 01385 \mathrm{~d}$

rsc.li/pccp

\title{
Quantifying the hygroscopic properties of cyclodextrin containing aerosol for drug delivery to the lungs $\dagger$
}

\author{
C. P. F. Day, (D) A. Miloserdov, K. Wildish-Jones, E. Pearson and A. E. Carruthers (D)*
}

\begin{abstract}
Aerosol dynamics is important to quantify in drug delivery to the lungs with the aim of delivering therapeutics to a target location and optimising drug efficacy. The macrocycle (2-hydroxypropyl)- $\beta$ cyclodextrin (2-HP- $\beta-\mathrm{CD}$ ) is thought to alleviate symptoms associated with neurodegenerative diseases when inhaled but the hygroscopic response is not well understood. Here we measure the hygroscopic growth of individual aqueous aerosol containing $2-\mathrm{HP}-\beta-\mathrm{CD}$ in optical tweezers through analysis of morphology-dependent resonances arising in Raman spectra. Droplets are analysed in the size range of 3-5 $\mu \mathrm{m}$ in radius. The evolving radius and refractive index of each droplet are measured in response to change in relative humidity from $98-20 \%$ to determine mass and radius based hygroscopic growth factors, and compared with dynamic vapour sorption measurements. Bulk solution refractive index and density measurements were used in accordance with the self-consistent Lorenz-Lorentz rule to determine melt solute and droplet properties. The refractive index of $2-\mathrm{HP}-\beta-\mathrm{CD}$ was determined to be $1.520 \pm 0.002$ with a density of $1.389 \pm 0.005 \mathrm{~g} \mathrm{~cm}^{-3}$. To our knowledge, we show the first aerosol measurements of $2-\mathrm{HP}-\beta-\mathrm{CD}$ and determine hygroscopicity. By quantifying the hygroscopic growth and physicochemical properties of $2-\mathrm{HP}-\beta-\mathrm{CD}$, the impact of aerosol dynamics can be accounted for in tailoring drug formulations and informing models used to predict drug deposition patterns within the respiratory system.
\end{abstract}

\section{Introduction}

Determining and controlling aerosol properties is important for targeted and effective drug deposition patterns where the environment of the drug path towards and into the respiratory tract or through the olfactory system is known to influence pharmaceuticals. ${ }^{1}$ A poor understanding of the relationship between the physicochemical characteristics of aerosol formulation and the medicinal efficacy in the humid environment of the respiratory tract has been identified as the key barrier in optimising inhalation therapies. ${ }^{2}$ Recent studies have shown characterisation of the physiochemical properties of aerosolised medicinal agents used in drug delivery to the lung, e.g. salbutamol sulphate, ${ }^{3}$ where the aging of the droplet as it responds to rapid changes in $\mathrm{RH}$ and temperature during inhalation is known to significantly impact aerosol properties. Such studies demonstrate the importance of quantifying the hygroscopic response to predict particle deposition patterns within the pulmonary system.

Chemistry, School of Natural and Environmental Sciences, Bedson Building,

Newcastle University, Newcastle Upon Tyne, NE1 7RU, UK.

E-mail: toni.carruthers@ncl.ac.uk

$\dagger$ Electronic supplementary information (ESI) available. See DOI: 10.1039/d0cp01385d
On inhalation, aerosol radii of $\geq 5 \mu \mathrm{m}$ are more likely to deposit in the mouth and throat, $<5 \mu \mathrm{m}$ will travel to the lung, and particles $<1 \mu \mathrm{m}$ are thought to be predominantly exhaled.,4

For a drug molecule to be pharmacologically active it may be designed to have lipophilic properties to allow absorption and diffusion through biological membranes, and be hydrophilic to improve water solubility. Cyclodextrins (CD) have been identified as medicinal agents for use in drug inhalation formulations and can enable the controlled release of drugs. ${ }^{5}$ They are useful excipients because their physiochemical properties can be tuned through molecular modification to improve hydrophilicity and bioavailability. CDs are macrocycles that consist of a hydrophilic exterior and lipophilic interior that can selectively complex with inorganic and organic molecules in aqueous solution. These properties enable cyclodextrins to carry drug molecules in solution, delivering them to the surface of biological membranes. ${ }^{6}$ Naturally occurring CDs are cyclic oligomers of glucopyranose, containing six $(\alpha-C D)$, seven $(\beta-C D)$ and eight $(\gamma-C D)$ glucopyranose units connected by glucosidic bonds. The smaller inner cavity size of $\alpha$-CD can be a limiting factor for complexation with large drug molecules and the larger cavity of $\gamma$-CD typically does not offer enough complexation stability. ${ }^{7}$ Studies have therefore focussed on $\beta$-CD, and in particular modifying $\beta$-CD to improve its 
unwanted tendency to aggregate and unusually low water solubility. ${ }^{8,9}$ Molecular modelling suggests that low hydrophilicity stems from intermolecular bonding in the natural $\beta$-CD crystal state that affects the rigidity of the molecule and induces strong ordering on the surrounding water molecules. ${ }^{10}$ In comparison, the position of hydroxyl groups in the modification site of the parent CD in (2-hydroxypropyl)- $\beta$-cyclodextrin (2-HP- $\beta$ $\mathrm{CD})$ have been shown through molecular docking models ${ }^{7}$ to slightly reduce the size of the cavity and allow hydrogen bonding with external neighbouring water molecules in aqueous solution. 2 -HP- $\beta$-CD therefore has improved water solubility over the parent compound and is well suited to pharmaceutical and environmental applications. Furthermore, the porous nature of CD molecules and their amphiphilicity makes them a highly interesting structure to investigate hygroscopic response. Potential formation of amorphous phases observed in CDs may reveal interesting water kinetics that can impact droplet concentration and drug uptake in the lungs. Studying hygroscopicity of aerosol in femtolitre to picolitre volumes, where the droplet surface area to volume ratio is favourable, can provide insight into chemistry occurring at the surface and on a molecular level.

Aerosol consist of microscopic and sub-microscopic particles and droplets dispersed in a gas medium that evolve dynamically to equilibrate with the surrounding environment. They are thermodynamically unstable due to their large surface area but can be kinetically stabilised with respect to relative humidity $(\mathrm{RH})$, where $\mathrm{RH}$ is the partial pressure of water vapour in the gas phase compared to the vapour pressure of pure water. The behaviour of aerosol can deviate from that expected in a bulk solution, offering higher concentrations, metastable states and extreme $\mathrm{pH}$ values that help drive chemical reactions. ${ }^{11}$ Aerosol respond to an increase or decrease in $\mathrm{RH}$ inducing a change in the number of water molecules in the atmosphere and vapour pressure of the droplet. This $\mathrm{RH}$ change drives the droplet towards reaching equilibrium in terms of size, concentration and phase (e.g. liquid, glass, gel). A dry and hygroscopic aerosol particle held at low $\mathrm{RH}$, close to $\mathrm{RH}=0 \%$, will respond immediately to a driven and controlled atmosphere. As RH increases, the water vapour around the aerosol particle also increases and creates a net flux of water molecules towards the aerosol surface. The continual increase in $\mathrm{RH}$ brings the aerosol towards the saturation point of the bulk solution where water molecules adsorb onto the particle surface and are accommodated, known as deliquescence. This uptake of water induces a phase change of the aerosol from solid to liquid. The droplet will continue to take up water with a further increase in $\mathrm{RH}$ that increases the droplet size as the mass fraction of water (MFW) in the droplet increases. Correspondingly, the mass fraction of solute (MFS) in the droplet decreases, i.e. $\mathrm{MFS}+\mathrm{MFW}=1$, and droplet refractive index (RI) tends towards that of water as $\mathrm{RH}$ approaches $100 \%$. On responding to a decrease in $\mathrm{RH}$, the droplet can exist in a liquid state beyond the deliquescence point (i.e. at lower RHs) because there is no site on which nucleation can take place, and the MFS of the droplet can exceed that of a bulk solution. The aerosol is then said to exist in a highlyconcentrated super-saturated state and is the region where meta-stable phases can form that exhibit interesting water uptake kinetics. $^{12,13}$ The hygroscopic evolution of an aerosol droplet therefore ranges from the dilute limit to that of a pure liquid solute or melt, ${ }^{14}$ which we refer to here as melt solute. Hygroscopic growth curves, also referred to as humidity isotherms for bulk sample measurements, are characteristic of aerosol composition. Here we measure the hygroscopic growth of (2-hydroxypropyl)- $\beta$-cyclodextrin (2-HP- $\beta$-CD) which, as a medicinal agent, is thought to alleviate symptoms associated with neurodegenerative diseases for use in drug inhalation formulations. ${ }^{1,15,16}$ The hygroscopicity of microscopic sized aerosol droplets is determined on a single droplet basis using Raman tweezers ${ }^{17,18}$ and compared with dynamic vapour sorption (DVS) humidity isotherm measurements. ${ }^{19,20}$

As an excipient, 2-HP- $\beta$-CD is used in developing environmentfriendly formulations removing polycyclic aromatic hydrocarbons (PAHs) from soil ${ }^{21}$ and has shown to complex with heavy metals, ${ }^{6}$ small organic guest molecules ${ }^{22}$ and acetanilides. ${ }^{23}$ In ref. 24 the concentration of HP- $\beta$-CD was found to increase linearly when complexed with PAHs, and is thought to have no critical micelle concentration. In the form of nanofibers, HP- $\beta$-CD has shown to improve the molecular entrapment of VOCs, potentially serving as a filtering material in air filtration applications. ${ }^{25}$ In drug delivery applications $2-\mathrm{HP}-\beta-\mathrm{CD}$ is thought to have significant medicinal benefits in alleviating symptoms of neurodegenerative disorders, e.g. Alzheimer's, Neimann Pick's, Parkinson's and Huntington's diseases, when inhaled. ${ }^{15,16}$ The commercially available Kleptose ${ }^{\circledR}$ $10(\beta-\mathrm{CD})$ has been developed as an attractive excipient for nasal and pulmonary drug administration, and Kleptose ${ }^{\circledR}$ HPB (HP- $\beta$ CD) for alternative delivery routes. ${ }^{26}$ Erickson et al. ${ }^{27}$ used a mouse model where a $20 \%$ HP- $\beta$-CD in saline solution was used to assess the inhaled therapeutic potential in Neimann-Pick type C1 disease and drug impact on the lungs. Further studies have shown complexation of pulmonary delivered HP- $\beta$-CD with salbutamol in rabbits, ${ }^{28}$ where the use of HP- $\beta$-CD provides tuneability of active drug hydrophilicity. Aerosolised CDs used in this way can help alleviate site toxicity issues associated with dry powder inhaler formulations. Determining aerosol response to change in $\mathrm{RH}$ is crucial in qualifying and quantifying hygroscopicity and understanding how this influences physiochemical properties such as size, concentration and phase (e.g. liquid, solid, glass, gel).

Despite the interest in CDs as medicinal agents and excipients, the physiochemical properties of CDs and CD derivatives, for example hygroscopicity, RI and density are ill-defined or unknown, and there is a need to understand the underlying aerosol science impacting inhaled formulation. ${ }^{2,3}$ Qualifying and quantifying aerosol hygroscopic response is key to improving drug formulations and informing models used to predict drug deposition patterns within the lung or taken up through the olfactory system. The use of optical tweezers is a well-established technique often coupled with Raman spectroscopy to quantify physiochemical properties of microscopic droplets and particles. ${ }^{17,29-31}$ By studying droplets on an individual basis, detailed information can be retrieved that is often over-looked from aerosol ensemble measurements due to averaging effects. Optical tweezers are well suited to enable characterisation of microscopic droplets of a size relevant to inhalation into the lung. The aerosol droplets measured with 
optical tweezers and discussed here range between 3-5 $\mu \mathrm{m}$ in radius. The position of morphology dependent resonances (MDRs), also known as whispering gallery modes, arising over the chemical $\mathrm{OH}$ and $\mathrm{CH}$ stretches observed in Raman spectra can be measured and used to determine droplet radius, RI and dispersion in RI. A least squares fit to minimise the error is used matching experimentally obtained MDRs to Mie theory calculations and described in detail by Preston and Reid. ${ }^{32,33}$ The hygroscopicity of the aerosol can then be determined through knowledge of the MFS of the droplet at a given RH. Bulk solution measurements are used to infer aerosol properties at high concentrations, and for that of the melt solute, and it is important that there is a physical basis to inform measurement. In the measurements presented here, the RI and density of aqueous 2 -HP- $\beta$-CD were measured with varying MFS in bulk solution to infer concentrations relevant to aerosol. The solution density measurements allowed determination of melt solute density using the two-component mixing rule. The RI of solute was then retrieved using the self-consistent LorenzLorentz medium approximation, derived from the ClausiusMossotti relation. ${ }^{34}$

\section{Methods and materials}

\subsection{Determining growth factors and the mass based hygroscopicity parameter}

The hygroscopic response of aerosol is often described in terms of mass $\left(\mathrm{GF}_{\mathrm{m}}\right)$ and radius $\left(\mathrm{GF}_{\mathrm{r}}\right)$ based growth factors that can be converted between where density or RI are known. ${ }^{18,35}$ Through control of the $\mathrm{RH}$ around a droplet MFS can be tuned by initiating a change in the droplet water activity. This drives the droplet dynamically to equilibrate with the surrounding $\mathrm{RH}$ resulting in a change in size, RI, density and MFS. Equilibrium is reached once the vapour pressure at the droplet surface reaches that of the partial vapour pressure an infinite distance away from the droplet. Eqn (1) is valid for particle sizes $>1 \mu \mathrm{m}$ where the surface curvature of droplets do not play a significant role and water activity can be approximated as $a_{\mathrm{w}} \approx \mathrm{RH} / 100 .^{35}$

$$
\mathrm{GF}_{\mathrm{m}}=\frac{m_{\mathrm{wet}}}{m_{\mathrm{dry}}}=\frac{1}{\mathrm{MFS}}=1+\kappa_{\mathrm{m}}\left(\frac{a_{\mathrm{w}}}{1-a_{\mathrm{w}}}\right)
$$

The wet and dry masses of the aerosol are denoted $m_{\text {wet }}=$ $m(\mathrm{RH}>0 \%)$ and $m_{\mathrm{dry}}=m(\mathrm{RH}=0 \%)$, respectively. $\mathrm{GF}_{\mathrm{m}}$ is determined and converted to the mass based hygroscopicity parameter, $\kappa_{\mathrm{m}}$. The hygroscopicity parameter is a function of the mass of water present and dependent on solute composition, where $\kappa_{\mathrm{m}}$ approaching zero at high $\mathrm{RH}$ values $(\mathrm{RH} \rightarrow 100 \%)$ indicates a poorly hygroscopic compound. ${ }^{18,35} \kappa_{\mathrm{m}}$ is more significant at higher $\mathrm{RH}$ values in the dilute ideal limit, where it becomes independent of MFS. The hygroscopicity parameter can be expressed as eqn (2) written in terms of MFS.

$$
\kappa_{\mathrm{m}}=\left(\frac{1}{a_{\mathrm{w}}}-1\right)\left(\frac{1-\mathrm{MFS}}{\mathrm{MFS}}\right)
$$

The radius based growth factor, $\mathrm{GF}_{\mathrm{r}}$ can be determined from $\mathrm{GF}_{\mathrm{m}}$ using the density of the droplet, $\rho_{\text {drop }}$, and melt solute density, $\rho_{\mathrm{s}}$, eqn (3). ${ }^{18}$

$$
\mathrm{GF}_{\mathrm{r}}=\left(\mathrm{GF}_{\mathrm{m}} \frac{\rho_{\mathrm{s}}}{\rho_{\text {drop }}}\right)^{1 / 3}
$$

Here we characterise the hygroscopic growth response and physiochemical properties of aqueous 2 -HP- $\beta$-CD aerosol droplets and compare these with DVS measurements.

\subsection{AIOMFAC modelling and hygroscopicity order}

Hygroscopicity can be modelled using AIOMFAC (Aerosol InorganicOrganic Mixtures Functional groups Activity Coefficients), a thermodynamic model based on UNIFAC calculations. ${ }^{36,37}$ The AIOMFAC model allows properties such as the mass fraction of water (MFW) and solute (MFS) of the droplet to be predicted at each RH value based on the assignment of functional groups. The AIOMFAC curves predict the evaporative hygroscopic response of aerosol, i.e. as $\mathrm{RH}$ is decreased. The hygroscopicity of the aerosol composition can then be determined in terms of $\mathrm{GF}_{\mathrm{m}}, \kappa_{\mathrm{m}}$ and $\mathrm{GF}_{\mathrm{r}}$ at a defined temperature. It is worth noting that structural information is not included in AIOMFAC and predicted hygroscopicities are thought to deviate from experimental measurements for large and complex molecules. ${ }^{38}$ For purposes of AIOMFAC modelling, we have restricted discussion of CDs to the three parent compounds ( $\alpha-\mathrm{CD}, \beta-\mathrm{CD}$ and $\gamma-\mathrm{CD})$, the derivative HP- $\beta$-CD and glucopyranose (as representative of one repeat unit of the cyclic sugars). The hygroscopicity of all molecules discussed here have been predicted at $T=25{ }^{\circ} \mathrm{C}$ to coincide with DVS measurements.

The HP- $\beta$-CD ring contains seven repeat units, with a chemical formula of $\left(\mathrm{C}_{9} \mathrm{H}_{16} \mathrm{O}_{6}\right)_{7}$. For purposes of AIOMFAC modelling the functional groups within the HP- $\beta$-CD molecule are assigned according to ref. 36, as are a single glucopyranose unit, $\alpha$-CD, $\beta$-CD and $\gamma$-CD (see ESI $\dagger$ for functional group assignments). AIOMFAC modelling of the parent compounds $\alpha$-CD, $\beta$-CD and $\gamma$-CD show similar trends in terms of MFS, $\kappa_{\mathrm{m}}$ and $\mathrm{GF}_{\mathrm{m}}$ with respect to $\mathrm{RH}$, Fig. 1. An insert of the $\mathrm{GF}_{\mathrm{m}}$ values obtained at higher RHs is shown to clarify the predicted order

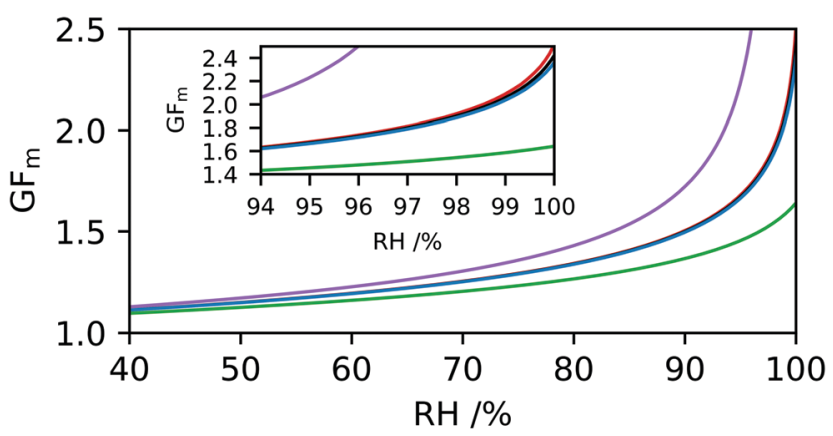

Fig. 1 AIOMFAC modelling showing growth factors $\mathrm{GF}_{\mathrm{m}}$ as a function of relative humidity, $\mathrm{RH}$, and indicating deviation from expected behaviour for $\alpha-C D$ (red), $\beta-C D$ (black), $\gamma-C D$ (blue), glucopyranose (purple) and $2-H P-\beta-C D$ (green). 
Table 1 The chemical formula, solubility molecular mass and $\mathrm{O} / \mathrm{C}$ ratio are shown for $\alpha, \beta$ and $\gamma$ cyclodextrins (CD), the derivative hydroxypropyl$\beta$-cyclodextrin (HP- $\beta-C D$ ) and glucopyranose. References for solubility literature values of CDs are taken from Loftsson ${ }^{41}$ and Gidwani and Vyas ${ }^{42}$

\begin{tabular}{lllll}
\hline Cyclodextrin & $\begin{array}{l}\text { Chemical } \\
\text { formula }\end{array}$ & $\begin{array}{l}\text { Solubility } \\
\left(\mathrm{mg} \mathrm{mL}^{-1}\right)\end{array}$ & $\begin{array}{l}\text { Molecular mass } \\
\left(\mathrm{g} \mathrm{mol}^{-1}\right)\end{array}$ & $\mathrm{O} / \mathrm{C}$ \\
\hline$\alpha$-CD & $\left(\mathrm{C}_{6} \mathrm{H}_{10} \mathrm{O}_{5}\right)_{6}$ & 145 & 972.8 & 0.83 \\
$\beta$-CD & $\left(\mathrm{C}_{6} \mathrm{H}_{10} \mathrm{O}_{5}\right)_{7}$ & 18.5 & 1135 & 0.83 \\
$\gamma$-CD & $\left(\mathrm{C}_{6} \mathrm{H}_{10} \mathrm{O}_{5}\right)_{8}$ & 232 & 1297.1 & 0.83 \\
HP- $\beta$-CD & $\left(\mathrm{C}_{9} \mathrm{H}_{16} \mathrm{O}_{6}\right)_{7}$ & $\geq 600$ & 1541.6 & 0.67 \\
Glucopyranose & $\mathrm{C}_{6} \mathrm{H}_{10} \mathrm{O}_{5}$ & 1200 & 180.16 & 0.83
\end{tabular}

of hygroscopicity. It can be seen that AIOMFAC predicts HP- $\beta$-CD to be less hygroscopic than $\beta$-CD and suggests a hygroscopicity order of HP- $\beta$-CD $\ll \gamma$-CD $\sim \beta$-CD $\sim \alpha$-CD $\ll$ glucopyranose. These results indicate that strong ordering of $\beta$-CD on neighbouring water molecules cannot be accounted for using AIOMFAC, which is unsurprising given that the linear structure of glucopyranose and cyclic CD structural information are not included. The amphiphilic nature of CDs arises due to the inside of the torus being relatively hydrophobic and the outside hydrophilic. Neighbouring water molecules on the outside of the torus are therefore in a distinct environment compared to the high-energy bound water molecules on the inside of the structure and likely to impact hygroscopicity. Here we are not determining the chemical complexity of hygroscopicity order, but it serves to illustrate the limitations of current understanding and the need to support aerosol measurements with alternative experimental techniques, for example in ref. 39 and 40.

In interpreting predicted hygroscopicity of CDs from AIOMFAC it is useful to consider the compounds in terms of solubility, elemental $\mathrm{O} / \mathrm{C}$ ratio and molecular mass, thought to influence order, ${ }^{17,41-44}$ see Table 1 . The properties of modified $\beta$-CDs are not well defined in the literature and the solubility of HP- $\beta$-CD is indicated as $\geq 600 \mathrm{mg} \mathrm{mL}^{-1}$ in Loftsson $^{41}$ and Gidwani and Vyas, ${ }^{42}$ where the position of the hydroxypropylation has not been assigned. Blanford ${ }^{22}$ assigns HP- $\beta$-CD a much higher solubility value of $>800 \mathrm{mg} \mathrm{mL}{ }^{-1}$, and Saokham et al. ${ }^{7}$ reports solubility to be $>1200 \mathrm{mg} \mathrm{mL}^{-1}$. It should be noted here that the degree of substitution of CD in formulating HP- $\beta$-CD is thought to be important and each variant may be chemically distinct due to differences found arising in mass spectrometry. ${ }^{45}$ Commercially available functionalised CDs tend to be heterogeneous in nature, and there is likely to be batch-to-batch variation. In our experiments, we did not set out to determine the solubility limit of 2-HP$\beta$-CD. However, we observed complete solvation of $2-\mathrm{HP}-\beta-\mathrm{CD}$ in deionised water at a concentration of $600 \mathrm{mg} \mathrm{mL}^{-1}$ for temperatures between $22-25{ }^{\circ} \mathrm{C}$, and by simply warming the solution in our hands concentrations of up to $800 \mathrm{mg} \mathrm{mL} \mathrm{m}^{-1}$ could be achieved.

\subsection{Dynamic vapour sorption}

DVS is an analytical tool used to determine humidity isotherms and the moisture content of inorganic and organic compounds ${ }^{19}$ under controlled environmental conditions of $\mathrm{RH}$ and temperature. It is a technique commonly used to determine the stability of pharmaceutical and food products in different atmospheres to optimise storage conditions, ${ }^{20}$ and ideally suited for comparison with aerosol measurements. The DVS instrument (SMS DVS-1) is configured such that two balances are held in a climate chamber of controllable RH and temperature. The DVS relies on placing a pan containing the sample to be measured on one balance and an empty reference pan is placed on the second balance. Prior to each measurement, an empty pan was placed on the sample balance, the $\mathrm{RH}$ increased to $90 \%$ to remove static and the balance was tared. A sample of dry white 2 -HP- $\beta$-CD powder (CAS 128446-35-5, Cambridge Bioscience, purity $\geq 95 \%$ ) was placed into the pan and allowed to equilibrate in the balance to a dry $\mathrm{N}_{2}$ gas environment, $\sim \mathrm{RH}=0.4 \%$. Fig. 2 shows the mass and rate of change of mass with respect to time in response to relative humidity for a sample mass of $m_{\mathrm{o}}=0.6498 \mathrm{mg}$. The $\mathrm{dm} / \mathrm{d} t$ response of $2-\mathrm{HP}-\beta-\mathrm{CD}$, shown in Fig. $2(\mathrm{~b})$, provides a useful indication of phase change in the humidity isotherm, where positive and negative peaks are indicative of adsorption and desorption processes, respectively.

For the experiments described here, the $\mathrm{RH}$ was varied and monitored using a Rotronic $\mathrm{A} / \mathrm{H}$ hygrometer with a $\pm 1 \%$ accuracy, and the sample maintained at a constant temperature of $25 \pm$ $1{ }^{\circ} \mathrm{C}$. The DVS was used in $\mathrm{d} m / \mathrm{d} t$ mode that allows the $\mathrm{RH}$ to step increase or decrease in $\mathrm{RH}$ after the sample mass had stabilised to within a tolerance level of $\pm 0.001 \%$ over a time period of five minutes. Each RH step was set to a maximum time of $t_{\max }=$ 360 min such that if the sample had not stabilised in mass within this time the $\mathrm{RH}$ would continue to step. Where stabilisation in mass was not fully achieved at each set $\mathrm{RH}$ within time $t_{\max }$, the response of sample mass with time at each $\mathrm{RH}$ step was fitted to an exponential growth (adsorption) or decay (desorption) function to determine equilibration mass. All DVS
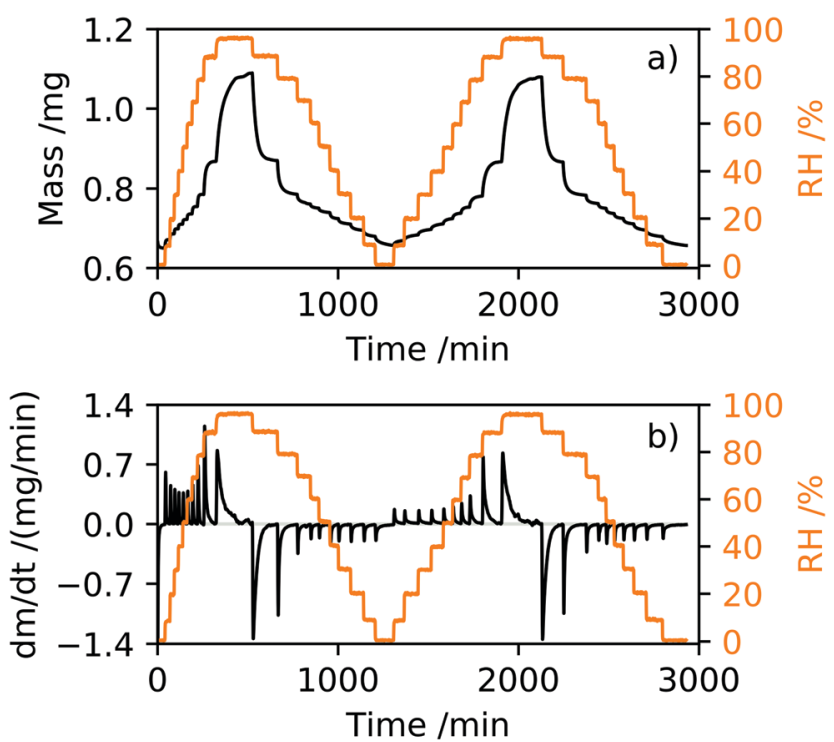

Fig. 2 The dynamic vapour sorption of two successive $2-\mathrm{HP}-\beta-\mathrm{CD}$ humidity isotherms are shown, measured up to $98 \% \mathrm{RH}$ for a dry sample mass of $0.6498 \mathrm{mg}$. The humidity isotherm is shown in terms of (a) mass (black) and (b) $\mathrm{d} m / \mathrm{d} t$ (black) in response to relative humidity (orange). 
measurements discussed here consisted of two adsorption and desorption cycles. The adsorption section of the humidity isotherm was recorded using 10\% RH steps from 0-90\% followed by a step from $90-98 \% \mathrm{RH}$, and the desorption followed the reverse $\mathrm{RH}$ stepping. Typical sample masses were prepared to be less than $1 \mathrm{mg}$ to reduce the potential for skin formation on the surface of the sample during measurement that might inhibit water uptake into the bulk of the sample.

\subsection{Optical tweezers coupled with cavity enhanced Raman spectroscopy}

Raman spectroscopy was integrated with optical tweezers to allow measurement of aerosol on a single particle basis. The laser used for optically tweezing droplets and Raman excitation was a diode-pumped solid-state laser (3W Opus, Laser Quantum) at a wavelength of $532 \mathrm{~nm}$. An LED of wavelength $447.5 \mathrm{~nm}$ allowed bright-field illumination of the droplet to observe the position stability of the droplet. Individual optically tweezed droplets were held in an environment chamber under controlled $\mathrm{RH}$ and at room temperatures ranging from $18-23{ }^{\circ} \mathrm{C}$. The spontaneous Raman signature collected provided information on the chemical properties of the aqueous droplet, and MDRs superimposed over the chemical bond vibrations were used to determine size, RI and dispersion in RI. ${ }^{32,33}$ Raman spectra were measured using an iHR550 Raman spectrometer (Horiba Scientific) and the droplet imaged onto a Peltier-cooled Syncerity CCD (Horiba Scientific). Spectra of aerosol droplets were recorded using an acquisition time of $10 \mathrm{~s}$, a diffraction grating of 600 grooves per $\mathrm{mm}$ and a slit width of $20 \mu \mathrm{m}$. The broad $\mathrm{OH}$ stretch arises in the Stokes shifted Raman spectra at $\lambda_{\mathrm{OH}} \approx$ $650 \mathrm{~nm}$, and the $\mathrm{CH}$ stretch at $\lambda_{\mathrm{CH}} \approx 630 \mathrm{~nm}$. A sample of dry powder 2 -HP- $\beta$-CD was recorded in the Raman spectrum placed on a coverslip to observe the underlying $\mathrm{CH}$ and $\mathrm{OH}$ stretches without the presence of MDRs, Fig. 3(a), and relative intensities of the vibration bands. A spectrum of an aqueous droplet held in optical tweezers and equilibrated to an $\mathrm{RH}$ of $80 \%$ is shown for comparison where MDRs are visible over the chemical stretches. The RI of the droplet is taken to be at reference wavelength of $\lambda_{\mathrm{OH}}=650 \mathrm{~nm}$ because this wavelength is close to the centre of the $\mathrm{OH}$ band where the majority of the MDRs lie and are used for sizing the droplet. Fig. 3(b) illustrates the MDR positions shifting to a lower wavelength in response to a change in $\mathrm{RH}$ from $98-90 \%$ and $70-60 \%$, and is indicative of size suppression caused by water evaporation away from the droplet. A least squares fit error analysis of experimental Raman spectra with Mie theory allows droplet radius and RI to be accurately determined, see Fig. 4. The uncertainty in radius and RI is estimated from minimising the error arising from matching MDR positions in each spectrum to a library of Mie theory calculations. The dispersion in RI, $\mu$, can be also be determined through analysis of MDR positions using Mie theory calculations ${ }^{32,33}$ and can be expressed in terms of wavelength in eqn (4), where $\mu$ is measured in $\mathrm{cm}^{-1}$.

$$
n_{\lambda_{\mathrm{Abbe}}}=n_{\lambda_{\mathrm{OH}}}+\mu\left(\frac{10^{7}}{\lambda_{\mathrm{Abbe}}}-\frac{10^{7}}{\lambda_{\mathrm{OH}}}\right)
$$
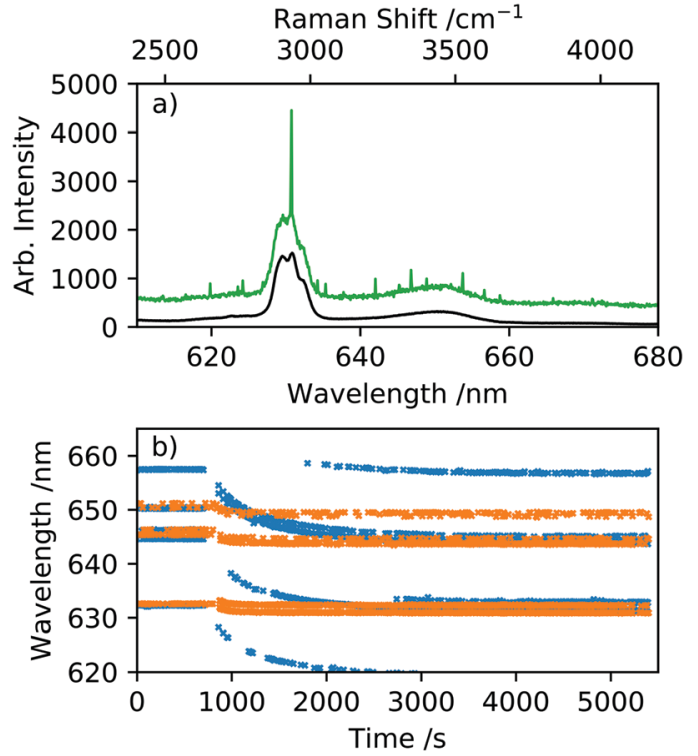

Fig. 3 (a) Raman spectrum of a $2-\mathrm{HP}-\beta-\mathrm{CD}$ droplet held using optical tweezers taken at $80 \% \mathrm{RH}$ shown in green, along with a bulk dry powder sample spectrum of $2-\mathrm{HP}-\beta-\mathrm{CD}$ shown in black. The intensities of the spectra have been adjusted to allow the spectra to be plotted together and for clarity of the bulk sample $\mathrm{CH}\left(\lambda_{\mathrm{CH}}=630 \mathrm{~nm}\right)$ and $\mathrm{OH}\left(\lambda_{\mathrm{OH}}=650 \mathrm{~nm}\right)$ stretches. (b) Morphology dependent resonance wavelength positions are shown for two $\mathrm{RH}$ changes from $98-90 \%$ (blue crosses) and 70-60\% (orange crosses). The modes shifting to a lower wavelength indicate an evaporative process occurring and the droplet reducing in size and increasing in RI.
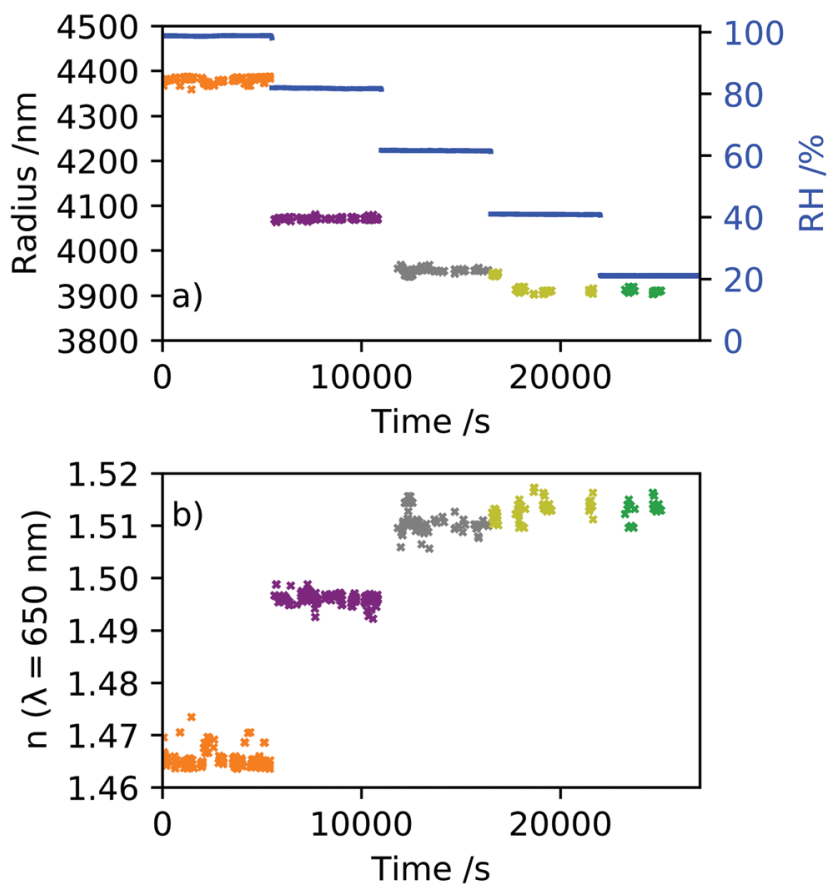

Fig. 4 An example droplet held in optical tweezers where the size and RI is determined from the morphology dependent resonances at different $\mathrm{RH}$ values (blue). For clarity of comparing and ease of viewing measurements, the equilibrated droplet data has been plotted using a time scale that is sequential, but not continuous. At each RH step, Raman measurements were recorded over 90 minutes. A minimum time period of 4 hours was allowed for droplet stabilisation to occur following a change in $\mathrm{RH}$. 
The RI of the droplet, $n_{\lambda_{\mathrm{OH}}}$, can then be dispersion corrected to the chosen wavelength of $\lambda_{\text {Abbe }}=589.3 \mathrm{~nm}$ used as the reference wavelength in Abbe refractometer and densitometer measurements. Solutions of aqueous 2 -HP- $\beta$-CD were measured at varying MFS to support optical tweezers measurements where aerosols typically exist at higher concentrations than that achievable in bulk solutions. These measurements allowed determination of the melt solute RI and density, and hygroscopic growth factors.

\subsection{Determining MFS of aerosol droplets}

Direct measurement of the density and RI of a powdered solute is not straightforward in aerosol, and techniques rely on indirect measurements and extrapolation to determine melt solute and highly viscous states. Methods used to retrieve RI, density and MFS need to be underpinned with a physical basis and with a well-defined relationship to determine aerosol characteristics in under-saturated and super-saturated regions of the hygroscopic growth curve. Knowledge of the melt solute properties can then be used to determine the MFS of the droplet where RI is known and can be written as a mixing rule, $n_{\text {droplet }}=n_{\mathrm{S}}$ MFS $+n_{\mathrm{w}}$ MFW. Such mixing rules assume that the melt solute RI and density values are used (rather than a stable crystalline form) and therefore valid for liquid and metastable glassy states of relevance to aerosol. ${ }^{14}$ The method chosen for extrapolating data to determine $\rho_{\mathrm{s}}$ and $n_{\mathrm{s}}$ (i.e. when MFS $=1$ ) has previously, to some extent depended on the fit of the data using linear and polynomial extrapolations. ${ }^{17,46,47}$ However, predicting aerosol properties of RI (optical density) and density (mass density) can be achieved using the Lorenz-Lorentz medium approximation. ${ }^{34}$ Written in eqn (5) in the form of molar refraction, $R$, the Lorenz-Lorentz rule can be used to determine $\mathrm{RI}$ and density where one of the properties is known. ${ }^{46,48}$

$$
R=\frac{\left(n^{2}-1\right)}{\left(n^{2}+2\right)} \frac{M}{\rho}=\frac{N_{\mathrm{A}} \alpha}{3}
$$

Here the molecular polarizability is denoted $\alpha, M$ is the molecular weight and $N_{\mathrm{A}}$ is Avogadro's constant. This formula describes a self-consistent relationship between RI $(n)$ and density $(\rho)$ of a substance and is valid for optically homogeneous and spherical molecules. The right-hand side term of eqn (5) containing polarisability remains unchanged as the droplet properties evolve with MFS. Molar refraction is therefore also constant with the combined properties of RI and density as written, and valid for aerosol existing at super-saturated RHs. The Lorenz-Lorentz rule can be re-written as eqn (6),

$$
\frac{\left(n^{2}-1\right)}{\left(n^{2}+2\right)}=\frac{N_{\mathrm{A}} \alpha}{3 M} \rho
$$

where plotting RI in the form of $\left(n^{2}-1\right) /\left(n^{2}+2\right)$ against density provides a linear trend. RI and density measurements of bulk solutions of $2-\mathrm{HP}-\beta-\mathrm{CD}$ in deionised water were recorded over a range of known MFS. $2-\mathrm{HP}-\beta-\mathrm{CD}$ is a white powder solid at room temperature and therefore the pure solute RI and density could not be measured directly using the instruments available. In these experiments, aqueous solutions were made up to a concentration of $600 \mathrm{mg} \mathrm{mL} \mathrm{m}^{-1}$ and the density and RI measured under serial dilution at a known temperature. The temperature of each measurement was recorded and the data compensated to $T=25^{\circ} \mathrm{C}$ to ensure all measurements were comparable and in line with the temperature of DVS measurements and AIOMFAC modelling. The measurements of density and RI can be found in the ESI. $\dagger$ Density measurements recorded using a densitometer (Metler Toledo densito 30PX) had an accuracy of $\pm 0.001 \mathrm{~g} \mathrm{~cm}^{-3}$, where the density of pure water was measured to be $\rho_{\mathrm{w}}=0.997 \mathrm{~g} \mathrm{~cm}^{-3}$ at $T=25{ }^{\circ} \mathrm{C}$. The density temperature correction factor was determined to be $1000 \times \gamma_{\rho}=0.1871 /{ }^{\circ} \mathrm{C}$, as detailed in the Metler Toledo manual and used to convert density between temperatures using $\rho_{25^{\circ} \mathrm{C}}=\rho_{\mathrm{T}}\left(1+\gamma_{\rho}(T-25)\right.$ ) (see ESI $\left.\dagger\right)$. Density measurements of aqueous 2-HP- $\beta$-CD solutions of known MFS were recorded and analysed using the two component mixing rule for density, eqn (7), written in terms of MFS. ${ }^{46,48}$

$$
\frac{1}{\rho_{\text {meas }}(1-\mathrm{MFS})}=\frac{\mathrm{MFS}}{\rho_{\mathrm{s}}(1-\mathrm{MFS})}+\frac{1}{\rho_{\mathrm{w}}}
$$

where the density of the measured bulk solution is denoted, $\rho_{\text {meas. }}$ In a similar fashion, the RI of each 2 -HP- $\beta$-CD solution prepared was measured using an Abbe refractometer (Metler Toledo refracto 30PX) at a reference wavelength of $\lambda=589.3 \mathrm{~nm}$. The temperature correction factor was determined to be $1000 \times$ $\gamma_{n}=0.3691 /{ }^{\circ} \mathrm{C}$, as described by the Metler Toledo manual, to allow conversion of RI's between temperatures using $n\left(25^{\circ} \mathrm{C}\right)=$ $n(T)+\gamma_{n}(T-25)$ (see ESI $\left.\dagger\right)$. For example, the RI of pure water was measured to be $1.334(\lambda=589.3 \mathrm{~nm})$ at $T=16.9{ }^{\circ} \mathrm{C}$, and temperature corrected to $n_{\mathrm{w}}=1.331$ at $25{ }^{\circ} \mathrm{C}$. The refractometer had a RI measurement accuracy of \pm 0.001 and the limit of detection was 1.50 at $25{ }^{\circ} \mathrm{C}$.

\section{Results}

\subsection{Refractive index and density measurements}

The density measurements with change in MFS were plotted such that the gradient of the line was equal to the reciprocal of the melt solute density, $1 / \rho_{\mathrm{s}}$, with a $y$-intercept of $1 / \rho_{\mathrm{w}}$, see Fig. 5(a). The pure solute melt density of 2 -HP- $\beta$-CD was determined for MFS $=1$ to be $\rho_{\mathrm{s}}=1.389 \pm 0.005 \mathrm{~g} \mathrm{~cm}^{-3}$ in Fig. 5(a) and the square of the correlation coefficient $R^{2}=0.9973$. These density measurements for bulk aqueous $2-\mathrm{HP}-\beta-\mathrm{CD}$ are in reasonable agreement with ref. 49 where aqueous solutions of HP- $\beta$-CD were measured at ambient room temperature up to a concentration of $800 \mathrm{mg} \mathrm{mL}{ }^{-1}$. For comparison, Girolami, ${ }^{50}$ used in aerosol model e-AIM ${ }^{51}$ where solute density is unknown, estimates a pure melt density for 2 -HP- $\beta$-CD of $1.245 \pm$ $0.200 \mathrm{~g} \mathrm{~cm}^{-3}$ at $T=25{ }^{\circ} \mathrm{C}$.

The densitometer and Abbe refractometer measurements were then used in accordance with the Lorenz-Lorentz rule in eqn (6), shown in Fig. 5(b). The data was fitted to a linear trendline and using the pure melt solute density obtained from the two-component mixing rule. The RI of pure solute was determined to be $n_{\mathrm{s}}=1.520 \pm 0.002\left(T=25{ }^{\circ} \mathrm{C}, \lambda=589.3 \mathrm{~nm}\right)$, where $R^{2}=0.9995$. To our knowledge, there is no solute RI literature value for 2 -HP- $\beta$-CD for comparison. 

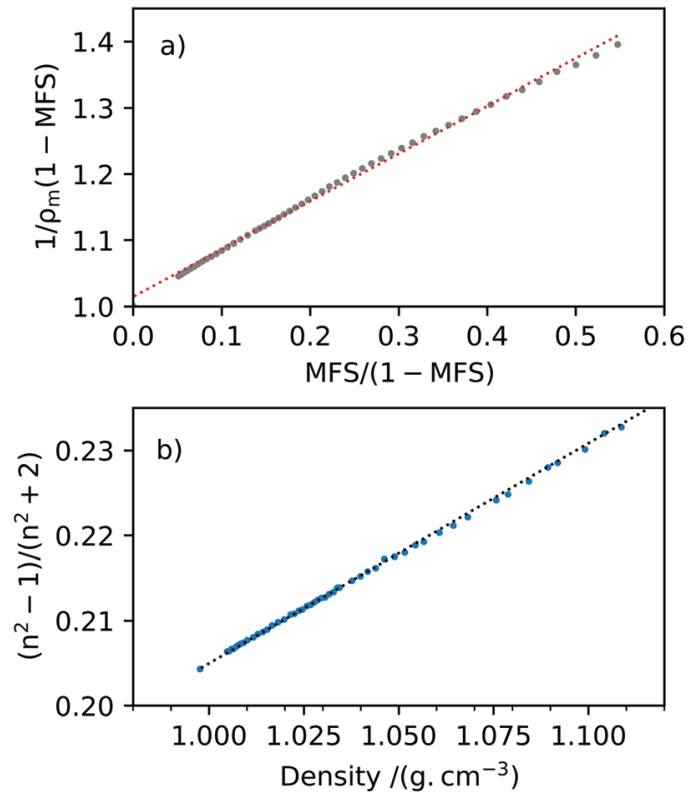

Fig. 5 Densitometer and refractometer measurements for aqueous 2 HP- $\beta$-CD solutions. (a) The two-component mixing rule for density was fit to a linear trend such that the gradient was the reciprocal of melt solute density, $1 / \rho_{\mathrm{s}}$ and the $y$-intercept equals the reciprocal of the density of water, $1 / \rho_{\mathrm{w}}$. The melt solute density was determined to be $\rho_{\mathrm{s}}=1.389 \pm$ $0.005 \mathrm{~g} \mathrm{~cm}^{-3}$, where the line of best fit is shown as a red dotted line. (b) The RI and density measurements are self-consistent with the LorenzLorentz rule when plotted as $\left(n^{2}-1\right) /\left(n^{2}+2\right)$ against density, and using $\rho_{\mathrm{s}}$ obtained from (a) a melt solute RI was determined to be $n_{\mathrm{s}}=1.520 \pm$ $0.002\left(\lambda=589.3 \mathrm{~nm}, T=25^{\circ} \mathrm{C}\right)$

\subsection{Dynamic vapor sorption hygroscopic growth measurements}

The extrapolated equilibrium mass values were obtained from the DVS measurement of $m_{\mathrm{o}_{-} 1}=0.6498 \mathrm{mg}$ for first and second adsorption and desorption profiles at each $\mathrm{RH}$ value. The growth factors at each RH value were calculated using eqn (1). Three further DVS measurements were recorded for samples of $m_{\mathrm{o} \_2}=0.6404 \mathrm{mg}, m_{\mathrm{o}_{-} 3}=0.4219 \mathrm{mg}$ and $m_{\mathrm{o}_{-} 4}=0.1765 \mathrm{mg}$ each consisting of two humidity isotherms and shown in Fig. 6 . The sensitivity of the mass microbalance was $0.0001 \mathrm{mg}$ and the precision associated with each individual mass measurement due to RH drift was less than $\pm 0.001 \mathrm{mg}$. The error bars shown on Fig. 6 indicate the deviation of the extrapolated mass value from the recorded raw data mass value. The accuracy in the $\mathrm{RH}$ originates from the hygroclip humidity probe of $\pm 1 \%$ that decreases to $\pm 2 \%$ at extremes of $\mathrm{RH}$, and we have conservatively assumed a $\pm 2 \%$ accuracy across RH measurements. At $90 \% \mathrm{RH}$, average growth factors for each sample were $\mathrm{GF}_{\mathrm{m}_{\_} 1}\left(m_{\mathrm{o}_{-} 1}=\right.$ $0.6498 \mathrm{mg})=1.337 \pm 0.004, \mathrm{GF}_{\mathrm{m} \_2}\left(m_{\mathrm{o} \_2}=0.6404 \mathrm{mg}\right)=1.176 \pm$ $0.0 .001, \mathrm{GF}_{\mathrm{m}_{-} 3}\left(m_{\mathrm{o} \_3}=0.4219 \mathrm{mg}\right)=1.284 \pm 0.008$ and $\mathrm{GF}_{\mathrm{m}_{-} 4}\left(m_{\mathrm{O} \_4}=0.1765 \mathrm{mg}\right)=1.388 \pm 0.005$. The DVS measurements allowed determination of MFS and $\kappa_{\mathrm{m}}$ of 2-HP- $\beta-\mathrm{CD}$ using eqn (1) and (2) and are shown in Fig. 6 with AIOMFAC modelling for comparison. In Fig. $3(\mathrm{~b}) \kappa_{\mathrm{m}}$ can be seen to curve as $\mathrm{RH}$ decreases and the contribution of dry mass in the sample becomes more significant. The range of hygroscopic GFs determined
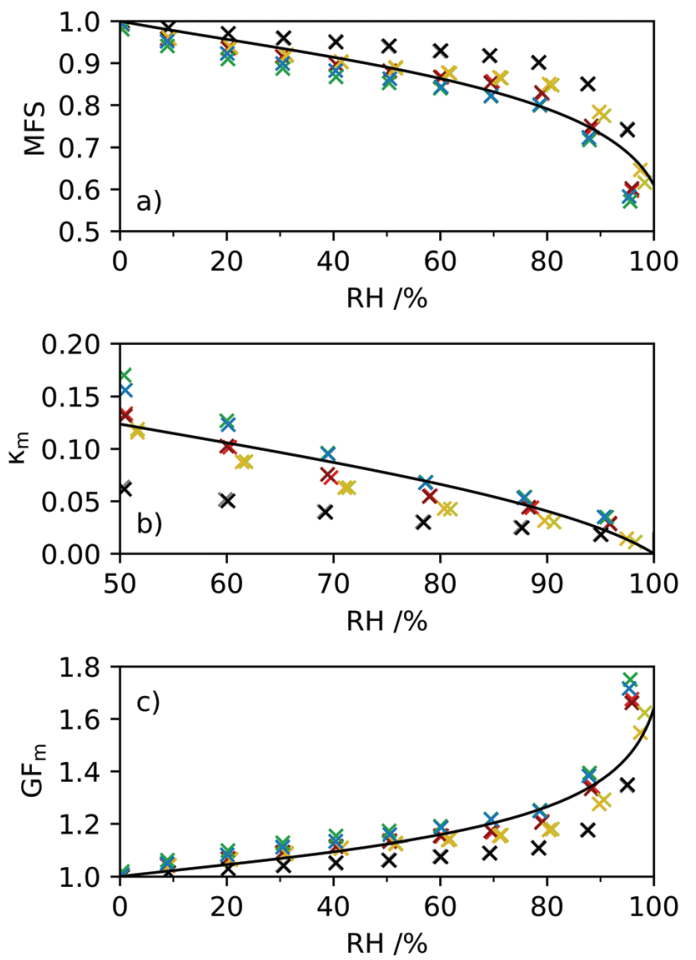

Fig. 6 The hygroscopic response of 2-HP- $\beta-C D$ is shown with a change in $\mathrm{RH}$ in terms of (a) mass fraction solute MFS, (b) the mass based hygroscopicity parameter $\kappa_{m}$, and (c) the mass based growth factor, $\mathrm{GF}_{\mathrm{m}}$. The desorption profile from $\mathrm{dm} / \mathrm{d} t$ mode dynamic vapour sorption (DVS) measurements is shown for four samples for which two humidity isotherms were measured. Starting masses shown are $m_{0_{-} 1}=0.6498 \mathrm{mg}$ as red (first desorption) and dark red (second desorption) crosses, $m_{\text {○_2 }}=0.6404 \mathrm{mg}$ as grey (first desorption) and black (second desorption) crosses, $m_{\mathrm{O}_{3} 3}=$ $0.4219 \mathrm{mg}$ as yellow (first desorption) and gold (second desorption) crosses, and $m_{\circ \_4}=0.1765 \mathrm{mg}$ as green (first desorption) and blue (second desorption) crosses. AIOMFAC modelling of $2-\mathrm{HP}-\beta-\mathrm{CD}$ is shown as a black line for comparison.

between successive DVS measurements is slightly surprising and may be a result of the choice to use mass samples of $<1 \mathrm{mg}$ due to the likelihood of heterogeneous variations between each sample.

\subsection{Optical tweezers hygroscopic growth measurements}

Raman spectra were recorded continuously over a time of $90 \mathrm{~min}$, with a minimum of 4 hours stabilisation time following each change in $\mathrm{RH}$. The radius and RI were determined from each spectrum, and a mean and standard deviation measurement obtained for each $\mathrm{RH}$ value. The relationships obtained between MFS, RI and density based on Abbe refractometer measurements were used to determine $\mathrm{GF}_{\mathrm{m}}$ of individual optically tweezed droplets. The RIs retrieved from optical tweezers measurements of five individual aerosol droplets are considered here, seen in Fig. 7. The RI and dispersion in RI fitting values for each droplet held at a given RH can be found in the ESI. $\dagger$ The RI values from each droplet were dispersion corrected to a wavelength of $589.3 \mathrm{~nm}$ using eqn (4). The growth factor measurements obtained through DVS are indicated with a grey area for clarity of optical tweezers data. AIOMFAC modelling is shown for comparison and 


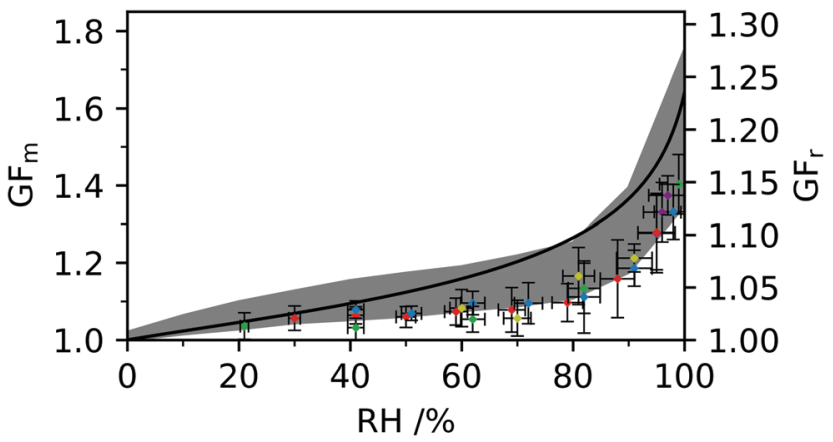

Fig. 7 The mass growth factor $\left(G_{m}\right)$ and radius growth factor $\left(G_{r}\right)$ are shown for five aerosol droplets measured using optical tweezers and indicated as diamond markers. DVS measurements are shown as a grey shaded area representative of the maximum and minimum values from the data discussed in Fig. 6 and AIOMFAC predictions are indicated as a black line.

in good agreement with the experimental data determined using optical tweezers and DVS techniques. The data was converted to $\mathrm{GF}_{\mathrm{r}}$ using eqn (3) for each data set.

\subsection{Amorphous phase formation}

During our optical tweezers and DVS measurements of 2-HP- $\beta$ CD we observed evidence of formation of a kinetically arrested state. The DVS samples were prepared using dry white solute powder, and observed post humidity isotherm measurement to be clear and highly viscous that hardened over time in ambient room atmosphere conditions. This observation was visually verified in the optical tweezers through a simplified pokeand-flow experiment. ${ }^{52}$ An aqueous 2 -HP- $\beta$-CD drop sample of concentration $600 \mathrm{mg} \mathrm{mL}^{-1}$ was placed on a coverslip and held at $98 \% \mathrm{RH}$ for three hours. The $\mathrm{RH}$ was then reduced to $30 \%$ $\mathrm{RH}$ to equilibrate over-night. The sample on the coverslip was removed from the optical tweezers $\mathrm{RH}$ environment chamber and observed to be clear and highly viscous. A pipette tip was used to poke the sample leaving an indentation, and left overnight in ambient room temperature and $\mathrm{RH}$. The sample was observed to harden to a clear solid and exhibited cracking behaviour with the poke indentation no longer visible. The measured hygroscopic response in terms of $\mathrm{GF}_{\mathrm{m}}$ using optical tweezers and DVS are also indicative of highly viscous particle formation, similar to optical tweezers measurements of sucrose measured by Tong et al. indicating a glass transition at $\sim 24 \%$ RH. ${ }^{53}$ During our measurements no crystallisation was observed to occur at low RH values, and the long timescales for equilibration indicative of slow water transport and formation of a kinetically arrested state. These observations are in agreement with previous work using molecular docking models that indicate water molecules can remain in the porous cavity of 2 -HP- $\beta$-CD on dehydration ${ }^{10}$ and in agreement with the amorphous complex formation of $2-\mathrm{HP}-\beta-\mathrm{CD}$ observed by Sonoda et $a .^{54}$ Water molecules could therefore be constrained to the inner cavity of 2 -HP- $\beta$-CD at low $\mathrm{RH}$ values, enabling amorphous transition and hydrated crystal formation as observed previously in $\alpha, \beta$ and $\gamma$ cyclodextrins. ${ }^{55}$

\section{Conclusions}

Hygroscopic measurements on aqueous 2 -HP- $\beta$-CD droplets have been reported using optical tweezers coupled with Raman spectroscopy. Aerosol properties are determined through analysis of the wavelength position of MDRs and compared with a library of Mie theory simulations to determine droplet radius, RI and dispersion in RI. Aerosol measurements have been compared with DVS humidity isotherm measurements and AIOMFAC modelling. Bulk RI and density measurements allowed determination of aerosol properties at high concentration using the Lorenz-Lorentz rule. The 2-HP- $\beta$-CD melt solute is self-consistent in RI and density with change in MFS in agreement with the Lorenz-Lorentz rule. Measurements indicate a solute melt density and RI of $1.389 \pm$ $0.005 \mathrm{~g} \mathrm{~cm}^{-3}$ and $1.520 \pm 0.002$, respectively. The hygroscopic growth factor of $2-\mathrm{HP}-\beta-\mathrm{CD}$ has been determined in terms of mass and radius, and is of significance in optimising drug inhalation formulations and medicinal efficacy. By quantifying hygroscopicity, aerosol dynamics can be exploited and properties tuned to ensure droplets are appropriately sized to reach the intended location in the lung or through the olfactory system on inhalation. Growth factor DVS measurements at $90 \% \mathrm{RH}$ indicate an average $\mathrm{GF}_{\mathrm{m}}(\mathrm{DVS})=1.30 \pm 0.08$ and is in good agreement with AIOMFAC modelling indicating $\mathrm{GF}_{\mathrm{m}}(\mathrm{AIOMFAC})=1.37$. In comparison, optical tweezers measurements provided a slightly lower $\mathrm{GF}_{\mathrm{m}}(\mathrm{OT})=1.22 \pm 0.06$ and $\mathrm{GF}_{\mathrm{r}}(\mathrm{OT})=1.08 \pm 0.05$, within error of DVS measurements. Slight discrepancy of optical tweezers $\mathrm{GF}_{\mathrm{m}}$ values with DVS measurements may have arisen from the determination of melt solute properties from bulk solution measurements. It is also worth noting that successive DVS measurements indicate a range of $\mathrm{GF}_{\mathrm{m}}$ values that can occur when samples undergo skin layer formation. An amorphous transition and formation of ultra-viscous aerosol has been identified through optical tweezers measurements and is in agreement with observations made from DVS measurements. The slow water transfer observed in amorphous cyclodextrin molecules coupled with their porous nature could reveal interesting water uptake kinetics in aerosol. Furthermore, cyclodextrins and cyclodextrin derivatives may provide valuable insight into understanding the chemical complexities of hygroscopicity and help in determining hygroscopic order.

\section{Conflicts of interest}

There are no conflicts to declare.

\section{Acknowledgements}

AEC acknowledges the Royal Society for early funding of the optical tweezers system through Research Grant RG130441. CPFD acknowledges Newcastle University for funding through a Research Excellence Award. We acknowledge Dr J. S. Walker and Prof. J. P. Reid in the School of Chemistry at the University of Bristol for the use of software used in aerosol analysis. Thank you to Prof. J. P. Reid for valuable comments on the manuscript. We thank Dr D. A. Fulton (Chemistry, School of Natural and 
Environmental Sciences, Newcastle University) for useful discussions on cyclodextrins and comments on the manuscript. We acknowledge the School of Pharmacy (Newcastle University) for use of the DVS and the School of Engineering (Newcastle University) for use of the refractometer and densitometer.

\section{References}

1 M. Vecsernyés, F. Fenyvesi, I. Bácskay, M. A. Deli, L. Szente and E. Fenyvesi, Arch. Med. Res., 2014, 45, 711-729.

2 N. R. Labiris and M. B. Dolovich, Br. J. Clin. Pharmacol., 2003, 56, 600-612.

3 A. E. Haddrell, J. F. Davies, R. E. H. Miles, J. P. Reid, L. A. Dailey and D. Murnane, Int. J. Pharm., 2014, 463, 50-61.

4 C. Darquenne, J. Aerosol Med. Pulm. Drug Delivery, 2012, 25, 140-147.

5 C. Muankaew and T. Loftsson, Basic Clin. Pharmacol. Toxicol., 2018, 122, 46-55.

6 E. M. Del Valle, Process Biochem., 2004, 39, 1033-1046.

7 P. Saokham, C. Muankaew, P. Jansook and T. Loftsson, Molecules, 2018, 23, 1161.

8 E. Sabadini, T. Cosgrove and F. do Carmo Egidio, Carbohydr. Res., 2006, 341, 270-274.

9 A. W. Coleman, I. Nicolis, N. Keller and J. P. Dalbiez, J. Incl. Phenom. Mol. Recognit. Chem., 1992, 13, 139-143.

10 K. J. Naidoo, J. Y. Chen, J. L. M. Jansson, G. Widmalm and A. Maliniak, J. Phys. Chem. B, 2004, 108, 4236-4238.

11 H. Wei, E. P. Vejerano, W. Leng, Q. Huang, M. R. Willner, L. C. Marr and P. J. Vikesland, Proc. Natl. Acad. Sci. U. S. A., 2018, 115, 7272-7277.

12 C. Cai, S. Tan, H. Chen, J. Ma, Y. Wang, J. P. Reid and Y. Zhang, Phys. Chem. Chem. Phys., 2015, 17, 29753-29763.

13 J. W. Lu, A. M. J. Rickards, J. S. Walker, K. J. Knox, R. E. H. Miles, J. P. Reid and R. Signorell, Phys. Chem. Chem. Phys., 2014, 16, 9819-9830.

14 S. L. Clegg and A. S. Wexler, J. Phys. Chem. A, 2011, 115, 3393-3460.

15 R. A. Rajewski and V. J. Stella, J. Pharm. Sci., 1996, 85, 1142-1169.

16 C. Coisne, S. Tilloy, E. Monflier, D. Wils, L. Fenart and F. Gosselet, Molecules, 2016, 21, 1748.

17 A. M. J. Rickards, R. E. H. Miles, J. F. Davies, F. H. Marshall and J. P. Reid, J. Phys. Chem. A, 2013, 117, 14120-14131.

18 E. Mikhailov, S. Vlasenko, D. Rose and U. Pöschl, Atmos. Chem. Phys., 2013, 13, 717-740.

19 I. Rörig-Dalgaard and S. Svensson, Rev. Sci. Instrum., 2016, 87, 054101.

20 L. Červenka, J. Kubínová, L. Juszczak and M. Witczak, Food Sci. Technol. Int., 2012, 18, 81-91.

21 E. Morillo, M. A. Sánchez-Trujillo, J. R. Moyano, J. Villaverde and M. E. Gómez-Pantoja, PLoS One, 2012, 7, e44137.

22 W. J. Blanford, J. Incl. Phenom. Macrocycl. Chem., 2013, 79, 57-64.

23 Q. Geng, J. Xie, X. Wang, M. Cai, H. Ma and H. Ni, J. Agric. Food Chem., 2018, 66, 12198-12205.
24 X. Wang and M. L. Brusseau, Environ. Sci. Technol., 1993, 27, 2821-2825.

25 A. Celebioglu, H. S. Sen, E. Durgun and T. Uyar, Chemosphere, 2016, 144, 736-744.

26 M. Ghadiri, P. M. Young and D. Traini, Pharmaceutics, 2019, 11, 113.

27 R. P. Erickson, G. Deutsch and R. Patil, J. Appl. Genet., 2018, 59, 187-191.

28 H. M. Cabral Marques, J. Hadgraft, I. W. Kellaway and G. Taylor, Int. J. Pharm., 1991, 77, 303-307.

29 R. E. H. Miles, A. E. Carruthers and J. P. Reid, Laser Photonics Rev., 2011, 5, 534-552.

30 L. Collard, D. Perez-Guaita, B. H. A. Faraj, B. R. Wood, R. Wallis, P. W. Andrew and A. J. Hudson, Sci. Rep., 2017, 7, 8589.

31 L. J. Moore, M. D. Summers and G. A. D. Ritchie, Phys. Chem. Chem. Phys., 2013, 15, 13489.

32 T. C. Preston and J. P. Reid, J. Opt. Soc. Am. B, 2013, 30, 2113-2122.

33 T. C. Preston and J. P. Reid, J. Opt. Soc. Am. A, 2015, 32, 2210-2217.

34 H. Kragh, Substantia, 2018, 2, 7-18.

35 M. D. Petters and S. M. Kreidenweis, Atmos. Chem. Phys., 2007, 7, 1961-1971.

36 A. Zuend, C. Marcolli, A. M. Booth, D. M. Lienhard, V. Soonsin, U. K. Krieger, D. O. Topping, G. McFiggans, T. Peter and J. H. Seinfeld, Atmos. Chem. Phys., 2011, 11, 9155-9206.

37 G. Ganbavale, A. Zuend, C. Marcolli and T. Peter, Atmos. Chem. Phys., 2015, 15, 447-493.

38 A. Marsh, R. E. H. Miles, G. Rovelli, A. G. Cowling, L. Nandy, C. S. Dutcher and J. P. Reid, Atmos. Chem. Phys., 2017, 17, 5583-5599.

39 H. S. Morris, A. D. Estillore, O. Laskina, V. H. Grassian and A. V. Tivanski, Anal. Chem., 2016, 88, 3647-3654.

40 A. D. Estillore, H. S. Morris, V. W. Orr, H. D. Lee, M. R. Alves, M. A. Marciano, O. Laskina, Z. Qin, A. V. Tivanski and V. H. Grassian, Phys. Chem. Chem. Phys., 2017, 19, 21101.

41 T. Loftsson, J. Incl. Phenom. Macrocycl. Chem., 2002, 44, 63-67.

42 B. Gidwani and A. Vyas, BioMed Res. Int., 2015, 2015, 198268.

43 M. Kuwata, S. R. Zorn and S. T. Martin, Environ. Sci. Technol., 2012, 46, 787-794.

44 J. Wang, J. E. Shilling, J. Liu, A. Zelenyuk, D. M. Bell, M. D. Petters, R. Thalman, F. Mei, R. A. Zaveri and G. Zheng, Atmos. Chem. Phys., 2019, 19, 941-954.

45 A. L. Yergey, P. S. Blank, S. M. Cologna, P. S. Backlund, F. D. Porter and A. J. Darling, PLoS One, 2017, 12, e0175478.

46 C. Cai, R. E. H. Miles, M. I. Cotterell, A. Marsh, G. Rovelli, A. M. J. Rickards, Y. Zhang and J. P. Reid, J. Phys. Chem. A, 2016, 120, 6604-6617.

47 B. J. Dennis-Smither, F. H. Marshall, R. E. H. Miles, T. C. Preston and J. P. Reid, J. Phys. Chem. A, 2014, 118, 5680-5691.

48 Y. Liu and P. H. Daum, J. Aerosol Sci., 2008, 39, 974-986. 
49 W. J. Blanford, M. L. Barackman, T. B. Boving, E. J. Klingel, G. R. Johnson and M. L. Brusseau, Groundwater Monit. Rem., 2001, 21, 58-66.

50 G. S. Girolami, J. Chem. Educ., 1994, 71, 962-964.

51 A. S. Wexler and S. L. Clegg, J. Geophys. Res., 2002, 107, 4207.

52 J. W. Grayson, E. Evoy, M. Song, Y. Chu, A. Maclean, A. Nguyen, M. A. Upshur, M. Ebrahimi, C. K. Chan, F. M. Geiger,
R. J. Thomson and A. K. Bertram, Atmos. Chem. Phys., 2017, 17, 8509-8524.

53 H.-J. Tong, J. P. Reid, D. L. Bones, B. P. Luo and U. K. Krieger, Atmos. Chem. Phys., 2011, 11, 4739-4754.

54 Y. Sonoda, F. Hirayama, H. Arima and K. Uekama, J. Incl. Phenom. Macrocycl. Chem., 2004, 50, 73-77.

55 E. Specogna, K. W. Li, M. Djabourov, F. Carn and K. Bouchemal, J. Phys. Chem. B, 2015, 119, 1433-1442. 